\title{
Health hazards of firefighters: acute pulmonary effects after toxic exposures
}

\author{
P W BRANDT-RAUF, ${ }^{1}$ B COSMAN, ${ }^{1}$ L FLEMING FALLON JR, ${ }^{1}$ T TARANTINI, ${ }^{2}$ \\ CATHY IDEMA ${ }^{2}$ \\ From the Division of Environmental Sciences, ${ }^{1}$ School of Public Health, Columbia University, New York, NY \\ 10032, and Tarantini Associates Ltd, ${ }^{2}$ New York, NY 10012, USA
}

\begin{abstract}
As part of an environmental monitoring and medical surveillance programme to evaluate potential health hazards from firefighting, complete baseline medical examinations were performed on a cohort of 77 firefighters. During a ten day study period, 37 follow up medical examinations were performed after exposure to fire to monitor any significant differences in pre-fire and post-fire physiological indices, including pulmonary function and blood counts and chemistries. For the group as a whole, no significant differences were found. For individuals not wearing respiratory protective equipment, however, statistically significant post-fire decrements in FEV 1 and FVC were noted. These decrements were consistent with previously shown levels of exposure to pulmonary toxicants in this cohort. These results support the need for more extensive use of respiratory protective equipment by firefighters.
\end{abstract}

With the increasing use of synthetic chemical based products in building construction in recent decades, there has been growing concern over the health hazards to firefighters from the inhalation of the toxic components of smoke.' Several studies of victims of smoke inhalation and firefighters have shown various acute health effects, particularly decrements in pulmonary function after exposure to smoke.' For example, Whitener et al studied pulmonary function in 28 patients after smoke inhalation and observed significant pulmonary obstruction within hours of exposure. ${ }^{2}$ Results of studies of firefighters have been similar. Musk et al studied 39 Boston firefighters after smoke inhalation and noted significant decrements in the forced expiratory volume at one second $\left(F_{E V}\right)$; $30 \%$ of the fire exposures caused a reduction in $\mathrm{FEV}_{1}$ of $100 \mathrm{cc}$ or more. ${ }^{3}$ Loke et al found an excess of changes in pulmonary function compatible with small airways disease (maximum expiratory flow-volume studies with helium/oxygen) in their study of 54 Connecticut firefighters, particularly in cigarette smokers or non-smoking firefighters with at least 25 years of service. ${ }^{4}$ Unger $e t$ al found persistent decreases in both $\mathrm{FEV}_{1}$ and forced vital capacity (FVC) in their study of 30 firefighters after severe smoke inhalation. ${ }^{5}$ A more recent study of 29 San Francisco firefighters showed not only a significant fall in $\mathrm{FEV}_{1}$ or FVC, or

Accepted 18 April 1988 both, in 18 of 76 pulmonary function measurements obtained within two hours of exposure to fire but also acute increases in airway responsiveness to methacholine challenge unrelated to baseline airway responsiveness. ${ }^{6}$ Several follow up studies of firefighters have raised the serious possibility that the observed acute alterations in pulmonary function may not always be temporary and reversible but that severe or repeated exposure to smoke may lead to chronic lung disease. $^{7-9}$

We have recently reported a personal environmental hygiene monitoring study of 51 firefighters that showed significant exposures of these firefighters to numerous toxic inhalants (including carcinogens, asphyxiants, particulates, and irritants) during the course of their routine firefighting duties. ${ }^{10}$ An extension of this study included medical surveillance of these firefighters with complete baseline medical examinations and follow up evaluations after each fire. This report presents the initial results of that medical surveillance with particular reference to the acute pulmonary effects noted in previous studies.

\section{Methods}

The cohort of firefighters studied consisted of 77 professional firefighters in five companies assigned to two firehouses in Buffalo, New York, who volunteered to participate in the environmental monitoring and 
medical surveillance programme. ${ }^{i 0}$ These firefighters were given a baseline medical evaluation that consisted of self administered general health questionnaire, physician administered occupational health questionnaire, physical examination, chest $x$ ray examination, electrocardiogram, pulmonary function testing $\left(\mathrm{FEV}_{1}\right.$ and FVC using a Collins spirometer model 1300 according to American Thoracic Society criteria), 24 hour urine collection and blood tests (complete blood count with differential, 12 routine serum chemistries, carboxyhaemoglobin level, and methaemoglobin level). They were then fitted out with personal environmental monitoring devices. As each firefighter in this cohort responded to a fire call, information was recorded on the time, date, and location of the fire, the company and firefighter responding to the incident, the type of personal monitoring performed, the activity performed (rescue, fire control, overhaul), characteristics of the fire (type of structure, material burning, smoke intensity), and the use of any respiratory protective equipment. After each fire, the firefighters were immediately taken for follow up testing which included all parts of the baseline evaluation except for the questionnaires, chest $x$ ray films, and urine collection. Thirty seven appropriate follow up examinations were completed during the 10 day period of the initial investigation, the remaining firefighters being unavailable during the study period owing to holidays, illness, or sick leave for follow up of abnormal baseline findings. As described previously, the study period encompassed 14 fire calls of sufficient duration and magnitude to warrant doing the environmental monitoring and medical surveillance, and these fires also yielded 26 usable personal exposure samples. $^{10}$

Differences in the pre-fire and post-fire values for each of the parameters measured were examined using the $t$ test for comparison of means of paired samples. Statistical significance was assumed for $p$ values less than 0.05 .

\section{Results and discussion}

The characteristics of the fires and the results of the personal monitoring have been presented previously. ${ }^{10}$ Of note are the facts that the fires included residential structures, industrial buildings, and an automobile and that significant levels of carbon monoxide, benzene, sulphur dioxide, hydrogen cyanide, formaldehyde, hydrogen chloride, various halogenated organics (dichlorofluoromethane, trichloroethylene, perchloroethylene, chloroform, methylene chloride, trichlorophenol), toluene, and particulates were found. Baseline medical evaluations were of note for the following abnormal findings: 24 of the 77 firefighters were found to have abnormal pulmonary
Brandt-Rauf, Cosman, Fallon, Tarantini, Idem $\overline{\bar{B}}$

function consistent with mild to moderate obstructiv disease, 14 raised blood pressure, one an abnormaf. density on chest radiography, 14 some minor electro cardiographic abnormality, 14 abnormal creatinine clearances, and 12 (all smokers) raised carboxye haemoglobin levels. These individuals were referres. for appropriate medical follow up and excluded fron further study.

Comparison of pre-fire and post-fire values for the्छ entire group of 37 paired measurements was done for the blood tests, $F_{E V}$, and FVC. No significant differences were found. Reasoning that individual $\overrightarrow{8 \Delta}$ wearing respiratory protective equipment may have्s thus successfully avoided any harmful exposures an resultant adverse clinical effects, the data wer? reanalysed for that group of individuals who did noक use any respiratory protective equipment at any time during the course of the fires. It should be noted thaD there were no differences in testing procedures betweep the firefighters who wore respiratory protective equip ment and those who did not. For this subgroup of $1 \overrightarrow{4}$ firefighters, comparison of pre-fire and post-fire FEV and FVC yielded significant differences. The average baseline value for this subgroup for $\mathrm{FEV}_{1}$ was 3.80 compared with an average follow up value of 3.611 , theo difference being statistically significant $(p \simeq 0.014)^{\circ}$ The corresponding pre-fire and post-fire values fo马 $\mathrm{FEV}_{1}$ for those wearing respiratory protection were 3.801 and 3.891 , respectively. The average baseline value for the unprotected group for FVC was 5.03 \$ compared with an average follow up value of $4.81 \frac{\mathbb{Q}}{2}$ again a statistically significant difference $(\mathrm{p} \simeq 0.007) \overrightarrow{\overrightarrow{0}}$ The corresponding pre-fire and post-fire values foB FVC for those wearing respiratory protection were 4.991 and 5.01 l, respectively. The magnitude of these़. changes is compatible with those noted in othe studies. ${ }^{36}$ In the cases where simultaneous persona $\mathbb{P}$ monitoring data were available the individuals not wearing respiratory protection were exposed to. significant levels of carbon monoxide, benzene particulates, and sulphur dioxide and lesser amounts of dichlorofluoromethane, trichloroethylene, chloroo form, perchloroethylene and toluene, as described previously ${ }^{10}$; observed levels of some of these-for example, sulphur dioxide at $2.5 \mathrm{ppm}$-are consisten with levels in other studies that have shown measuro able decrements in pulmonary function in exposed individuals. ${ }^{11-14}$ Levels of exposure to carbon mon oxide in these individuals ranged from 11 to $167 \mathrm{ppm}^{\mathrm{w}}$ and on medical examination five of the 14 individuals not wearing respiratory protective equipment were found to have increases in their carboxyhaemoglobirs levels, although the average difference for the group (1.5\% pre-fire $v 2.0 \%$ post-fire) did not achieve statistical significance. Two individuals were alsơ⿱ noted to have serious post-fire rises of their meth $\frac{\text { ? }}{\mathbb{D}}$ 
aemoglobin levels; however, no exposure to potentially responsible aliphatic or aromatic nitro or amino compounds could be documented, although such exposure could have occurred outside the period of environmental monitoring at those particular fires.

Previous investigators who have reported comparable findings in firefighters have concluded that personal respiratory protection for firefighters is inadequate to prevent the common occurrence of acute decrements in pulmonary function and therefore needs to be improved. ${ }^{6}$ The current findings, however, would tend to suggest that the personal respiratory protective equipment available to firefighters is perfectly adequate at least in terms of preventing acute decrements in pulmonary function when used in the appropriate circumstances. Unfortunately, it is not always clear to firefighters when the use of personal respiratory protective protection is necessary. As we have noted previously, the use of personal respiratory protection usually correlates with the visual impression of smoke intensity at a fire; however, the presence of significant concentrations of respirable toxic materials does not necessarily correlate with the impression of smoke intensity. ${ }^{10}$ Thus as noted in this study, firefighters are frequently exposed to toxic inhalants that result in measurable decrements in pulmonary function due to failure to use respiratory protective equipment. This observation would argue for the more extensive use of personal respiratory protection by firefighters regardless of the impression of hazard estimated by smoke intensity. Further study is necessary to document whether the observed acute effects in this study lead to increased morbidity and mortality from chronic lung disease, as has been suggested by others, or to other diseases such as cardiovascular disease (due to the documented carbon monoxide exposure) and cancer (due to the documented exposure to carcinogens including benzene, formaldehyde, and chlorinated hydrocarbons).

This work was made possible by grant $\mathrm{C} 001000 / 85055$ from the New York State Department of State in cooperation with the Association of New York State Professional Firefighters. In addition, one of the authors (LFF) was supported in part by NCI Cancer
Epidemiology, Biostatistics and Environmental Sciences Training Grant 5T32CA09529-02. We thank the members of the Buffalo Fire Department, State Fire Administrator Francis A McGarry, Dr A Aquilana, Erie County Medical Center, Dr J Zizzi, Erie County Health Department, Dr O SmithBlackwell, New York State Health Department; and the late Dr Melvin Schwartz who was instrumental in initiating this project.

\section{References}

1 Committee on Fire Toxicology. Fire and smoke: understanding the hazards. Washington: National Academy Press, 1986.

2 Whitener DR, Whitener LM, Robertson KJ, Baxter CR, Pierce AK. Pulmonary function measurements in patients with thermal injury and smoke inhalation. Am Rev Respir Dis 1980;122:731-9.

3 Musk AW, Smith TJ, Peters JM, McLaughlin E. Pulmonary function in firefighters: acute changes in ventilatory capacity and their correlates. Br J Ind Med 1979;36:29-34.

4 Loke J, Farmer W, Matthay RA, Putman CE, Smith GJW. Acute and chronic effects of firefighting on pulmonary function. Chest 980;77:369-73.

5 Unger KM, Snow RM, Mestas JM, Miller WC. Smoke inhalation in firemen. Thorax 1980;35:838-42.

6 Sheppard D, Distefano S, Morse L, Becker C. Acute effects of routine fire fighting on lung function. Am J Ind Med 1986;9: 333-40.

7 Peters JM, Theriault GP, Fine LJ, Wegman DH. Chronic effects of fire fighting on pulmonary function. $N$ Engl $J$ Med 1974;291:1320-2.

8 Peabody H. Pulmonary function and the fire fighters. Journal of Combustion Toxicology 1977;4:8-15.

9 Sparrow D, Bosse R, Rosner B, Weiss ST. The effect of occupational exposure on pulmonary function: a longitudinal evaluation of fire fighters and nonfire fighters. Am Rev Respir Dis 1982;125:319-22.

10 Brandt-Rauf PW, Fallon LF, Tarantini T, Idema C, Andrews L. Health hazards of firefighters: exposure assessment. $\mathrm{Br} \mathrm{J}$ Ind Med 1988;45:606-12.

11 Snell RE, Luchsinger PC. Effects of sulfur dioxide on expiratory flowrates and total respiratory resistance in normal human subjects. Arch Environ Health 1969;18:693-8.

12 Archer VE, Fullmer CD, Castle $\mathrm{CH}$. Sulfur dioxide exposure in a smelter. J Occup Med 1979;21:359-64.

13 Smith TJ, Peters JM, Reading JC, Castle CH. Pulmonary impairment from chronic exposure to sulfur dioxide in a smelter. Am Rev Respir Dis 1977;116:31-9.

14 Archer VE, Gillam JD. Chronic sulfur dioxide exposure in a smelter. J Occup Med 1978;20:88-95. 